\title{
A invisibilidade da sorodiscordância na atenção às pessoas com HIV/AIDS.
}

\section{The invisibility of serodiscordance in care for people with HIV/AIDS}

Angela Machado da Silva ${ }^{1}$

Kenneth Rochel de Camargo Junior ${ }^{1}$

${ }^{1}$ Instituto de Medicina

Social, Universidade do

Estado do Rio de Janeiro

(UERJ). Rua São Francisco

Xavier no 524/7\%/ Bl.D,

Maracanã. 20550-900 Rio

de Janeiro RJ.

angelamachado@

bighost.com.br

\begin{abstract}
This study seeks to identify and reflect on medical strategies used to ensure the systematic use of condoms for the effectiveness of AIDS prevention, in particular, when patients are involved in serodiscordant marital relationship in that only one of the partners is HIV positive. As analytical tools we used the concepts of thinking styles of epistemology (Fleck), the training process (Good), and therapeutics (Sayd, Camargo Jr. and Almeida). Among the findings of the research stood out an invisibility of the serodiscordant couples, for what turns out to be really important is adherence to treatment, which coincides with adherence to medication (ART).
\end{abstract}

Key words Serodiscordance, HIV/AIDS, Medical intervention, Biomedicine
Resumo Este estudo busca identificar e refletir sobre as estratégias médicas utilizadas a fim de garantir a importância do uso sistemático do preservativo na eficácia da prevenção à Aids, em especial, quando os pacientes estão envolvidos em relacionamentos conjugais sorodiscordantes, em que apenas um elemento do casal é portador do vírus HIV. Como instrumento de análise usamos os conceitos de estilos de pensamento da epistemologia (Fleck), de processo formativo (Good), e o de terapêutica (Sayd, Camargo Júnior e Almeida). Dentre os resultados encontrados na pesquisa, destacou-se uma invisibilidade dirigida aos casais sorodiscordantes, pois o que se revela como realmente importante é a adesão ao tratamento, que se confunde com adesão aos medicamentos (antirretrovirais).

Palavras-chave Sorodiscordância, HIV/Aids, Intervenção médica, Biomedicina 


\section{Introdução}

Esse artigo expressa alguns dos resultados obtidos na dissertação de mestrado de um dos autores ${ }^{1}$, e parte da preocupação com o caráter normativo e interventor da medicina na cultura e no cotidiano das pessoas, principalmente quando essa intervenção se debruça sobre aspectos íntimos e particulares dos indivíduos, como a sua vida conjugal/sexual. A eficácia da prevenção à Aids, pelo uso sistemático do preservativo, foi suficientemente demonstrada por diversas pesquisas, mas queremos identificar aqui quais as estratégias ou intervenções usadas pelos médicos para garantir aos seus pacientes a importância do seu uso. Em especial, quando esses pacientes estão envolvidos em relacionamentos conjugais sorodiscordantes, em que apenas um elemento do casal é portador do vírus HIV.

O sucesso dos recursos diagnósticos (exames) e terapêuticos (medicamentos) na condução do tratamento da infecção por HIV/Aids conferiu significativos benefícios aos portadores quanto ao aumento e à qualidade da expectativa de vida. Dessa forma, a epidemia vai mudando seu perfil e passa a se comportar de modo semelhante ao de uma doença crônica, com uma sobrevida dos portadores de HIV maior do que nos anos 1980 embora continue sendo uma doença que mata, principalmente as pessoas mais vulneráveis. A possibilidade do tratamento com acesso universal vem estimulando a reflexão das pessoas em relação à sua condição de saúde, à procura por serviços e à adesão ao seu tratamento ${ }^{1}$.

Os programas, governamentais ou não, dedicados a promover políticas não discriminatórias pregam que a Aids atinge a todos. A sexualidade abordada é a de todos, como se fôssemos igualados pelas mesmas práticas sexuais, sem sentidos particulares, sem contextos a serem considerados. O público-alvo dessas intervenções é o indivíduo soronegativo (sinônimo de "todos"), que deve se proteger de alguém potencialmente "soropositivo".

Chamamos a atenção quanto ao pouco preparo dos profissionais médicos, em especial os mais jovens, para abordar as questões da sexualidade. É este despreparo que gera insegurança, constrangimento ou fuga sobre o tema, no encontro com o paciente soropositivo.

[...] a Aids é duplamente desconfortável para a maior parte dos médicos, em primeiro lugar porque os coloca em frente a questões tabus como a sexualidade tida como desviante ou o uso de drogas ilícitas, questões para as quais não se encontram preparados, uma vez que até então elas não vinham sendo objeto de reflexão para o saber da medicina. Em segundo lugar, a informação sobre o modo de contágio depende única e exclusivamente da informação dos pacientes [...], o único referencial para possíveis contágios, desde o início da epidemia, é a palavra do paciente, no qual usualmente o médico não confia, por supor que o mesmo sempre mente, omite ou se equivoca ${ }^{2}$.

Com a descoberta da soropositividade, é comum ocorrer uma suspensão temporária das investidas afetivas e sexuais. Concordamos com Maksud $^{3}$ quando ela afirma que a revelação do status soropositivo pode representar a ruptura nos relacionamentos tradicionais; a redefinição dos papéis de gênero e o surgimento de identidades consideradas socialmente (aí incluídos os médicos) como "desviantes" (traidor ou infiel, homossexual, usuário de drogas, profissional do sexo, etc.).

Nos solteiros, a revelação da soropositividade traz o medo de não ser aceito pelo companheiro devido ao HIV, e, por esse motivo, o portador muitas vezes se cala e acaba por não exigir o preservativo nas suas relações sexuais, expondo o parceiro. Assim, é muito frequente que os portadores decidam se relacionar apenas com pessoas soropositivas, considerando ser este o único tipo de vínculo possível e na crença de que, dessa forma, podem dispensar o uso do preservativo. Considera-se essa prática insegura já que expõe ambos os parceiros, soropositivos, à troca de diferentes tipos de vírus HIV, podendo causar resistência aos medicamentos antirretrovirais prescritos ${ }^{3}$.

Entre os pacientes soropositivos que se encontram em relacionamentos conjugais considerados estáveis (homo ou heterossexuais), ocorre um sentimento de proteção e confiança entre os parceiros que não se sentem ameaçados pelo contágio do HIV, ocasionando um afrouxamento e/ ou suspensão do uso do preservativo em suas relações sexuais. Aliás, esta crença tem sido atualmente uma das maiores fontes de aquisição do HIV pelas mulheres, alterando o perfil epidemiológico da Aids, que em 1980 apresentava a relação de 25 homens afetados pelo HIV para $1 \mathrm{mu}$ lher afetada (25:1); em 1990, era de 6 homens para 1 mulher; em 2001, era de 2 homens para 1 mulher; e em 2006 essa relação continua a diminuir (1,4 homem para 1 mulher $)^{4}$.

Quando a parceria é composta por pessoas soropositivas, diz-se que elas estão num relacionamento soroconcordante. Ocorre, com frequência, a já citada crença equivocada de que se 
pode abrir mão do uso do preservativo, pois ambos possuem o vírus HIV. Quando apenas um elemento do casal é soropositivo e o outro é soronegativo, diz-se que a relação é sorodiscordante (ou 'sorodiferente'). Esses casais se isolam da família e dos amigos com receio de discriminação, e convivem com medo e culpa de colocar o parceiro em risco, expresso em pensamentos dirigidos ao soronegativo como "por que você está se relacionando com alguém HIV+?", "por que está se expondo a isto?”, e ao soropositivo como "por que você está expondo alguém ao risco de transmissão do HIV?". Há ainda outra questão delicada envolvendo especialmente esses casais, que é o desejo de engravidar, muitas vezes criticado, desconsiderado e condenado pelos profissionais de saúde, que os desaconselham a tentar pelo receio da ocorrência da transmissão vertical do HIV durante a gestação, no caso de a mulher ser soropositiva. Atualmente, o risco de infecção do HIV para o bebê nesses casos é de cerca de $2 \%$, desde que algumas medidas sejam devidamente aplicadas ${ }^{5}$.

As uniões de pessoas em relacionamentos conjugais estáveis envolvem afeto, cumplicidade, confiança, suporte emocional, elementos que podem ser aproveitados pelos profissionais de saúde para que os pacientes consigam enfrentar melhor o seu tratamento no combate ao HIV/ Aids. A condição de casal pressupõe uma certa negligência quanto ao uso sistemático do preservativo, culturalmente relacionado com relações extraconjugais ou com a prostituição, já que "casamento" geralmente envolve um modelo de fidelidade regido pela confiança recíproca ${ }^{6}$.

Nessa pesquisa, partiu-se da premissa de que a consideração das relações sorodiscordantes é um problema-limite, pois nesses casos a manutenção do status negativo do parceiro não infectado deve (ou deveria) merecer atenção específica e efetiva dos profissionais, dos serviços e das políticas de saúde. Apesar de esses casais relatarem uso sistemático do preservativo em suas relações sexuais, não deixam de ter dificuldades e barreiras de cunho cultural e emocional, que interferem na manutenção do sexo seguro. Dessa forma, os trabalhos de intervenção devem considerar os diversos fatores que deixam vulneráveis homens e mulheres (tanto do ponto de vista individual, como também no aspecto social do termo) ${ }^{1}$.

Autores como Ludwig Fleck ${ }^{7}$ e Byron Good ${ }^{8}$ nos permitem relacionar a biomedicina com essa discussão. A biomedicina se aproximou de um modelo de racionalidade científica que tem como referência a ampla valorização da técnica, pondo de lado aquilo que por ser subjetivo, complexo e variável, não é considerado científico nem verdadeiro, permitindo reduzir ao biológico todo o processo de adoecimento. Fleck ${ }^{7}$, pela perspectiva da epistemologia comparativa, reflete a construção do que é considerado um problema pelo saber biomédico a fim de perceber o estilo de pensamento presente entre os médicos. E Good ${ }^{8}$, com seu conceito de processo formativo, discute a formatação das intervenções e procedimentos médicos. A expressão “intervenção médica” está sendo utilizada aqui como algo que ultrapassa a ordem científica representada pela prescrição de medicamentos, mas inserida numa ordem ética que inclui o escutar, o examinar, a solicitação de exames, o aconselhamento, a dieta, e o interesse pelo jeito de viver do paciente ${ }^{9}$. Canguilhem ${ }^{10} \mathrm{e}$ Camargo Júnior ${ }^{11}$ apontam para a ação médica pautada numa teoria das doenças, construída sobre uma pretensa objetividade científica. Sayd $^{12}$, Camargo Júnior ${ }^{13}$ e Almeida ${ }^{9}$ discutem a ideia de terapêutica, atualmente quase reduzida ao uso de medicamentos, tanto para os médicos quanto para os pacientes.

Este trabalho está particularmente interessado em identificar e refletir sobre as estratégias médicas usadas para garantir a importância do uso sistemático do preservativo na eficácia da prevenção à Aids, em especial, quando os pacientes estão envolvidos em relacionamentos conjugais sorodiscordantes, em que apenas um elemento do casal é portador do vírus HIV.

\section{Metodologia}

Foi realizado um estudo qualitativo, de natureza exploratória, baseado na obtenção e na análise de depoimentos, utilizando-se a entrevista como ferramenta metodológica. O material encontrado neste estudo é resultado do discurso produzido pelo grupo de entrevistados, o que eles "dizem que fazem".

Considerando que a entrevista é uma situação de interação social sujeita à mesma dinâmica das relações existentes na nossa sociedade, neste trabalho, optou-se pela realização de entrevistas semiestruturadas, eficaz quando se trata de apreender sistemas de valores, normas e representações de determinado grupo social, ou quando se trata de compreender relações interpessoais ou institucionais ${ }^{14}$. A entrevista semiestruturada parte de um roteiro elaborado previamente que "serve de orientação, de baliza para o pesquisador, e não de cerceamento da fala dos entrevistados" ${ }^{15}$. 
Buscou-se apontar determinada realidade a partir de um movimento de mão dupla, que vai do material empírico à reflexão teórica e vice-versa.

$\mathrm{O}$ universo da pesquisa foi composto por seis médicos com experiência de trabalho em ambulatórios públicos, que prestam assistência às pessoas com HIV/Aids no município do Rio de Janeiro (RJ), em locais como hospitais universitários (HU), centros de testagem e aconselhamento (CTAs, serviços de saúde que realizam ações de diagnóstico e prevenção de Doenças Sexualmente Transmissíveis, onde é possível realizar gratuitamente testes para HIV, sífilis e hepatites B e C) ou serviços de assistência especializada ( $\mathrm{SAE}$, cujo objetivo é prestar um atendimento integral e de qualidade aos usuários por meio de uma equipe de profissionais de diversas áreas de saúde: médicos, psicólogos, enfermeiros, farmacêuticos, nutricionistas, assistentes sociais, educadores, entre outros). A escolha dos entrevistados obedeceu ao critério da indicação por outros médicos do círculo de relacionamento profissional dos autores (informantes privilegiados).

O recorte da categoria médica se relaciona com a importância do papel central desse profissional como responsável por elaborar e manter o tratamento do paciente e pela liderança da equipe de saúde quando havia uma. Alguns dos médicos entrevistados trabalhavam com pacientes soropositivos há mais de 10 anos (época do surgimento dos inibidores de protease na terapia antirretroviral). Uma das questões investigadas era, em que medida o tempo de experiência na assistência fazia diferença nos relatos sobre as estratégias utilizadas pelo grupo.

As entrevistas foram realizadas no período de outubro a dezembro de 2006, e ocorreram nos locais de preferência dos profissionais, seja no consultório particular, na clínica ou no serviço público. Todas foram gravadas com a permissão dos entrevistados, tendo sido transcritas posteriormente. As entrevistas foram analisadas com base no roteiro de entrevistas previamente elaborado, buscando identificar as falas relevantes para a elucidação das estratégias adotadas pelos médicos entrevistados. Cuidados éticos foram tomados quanto ao sigilo e à privacidade das informações colhidas. A experiência da pesquisadora responsável pelas entrevistas como psicoterapeuta foi aproveitada na condução das mesmas, visando interferir o mínimo possível e evitar ao máximo criar constrangimentos e inibições aos entrevistados.

Este estudo cumpre os princípios éticos envolvidos na pesquisa com seres humanos. Foi submetido à análise do Comitê de Ética em Pesquisa do Instituto de Medicina Social da Universidade do Estado do Rio de Janeiro (UERJ) e aprovado em 22/11/2006.

\section{Roteiro das entrevistas}

O roteiro funcionou como um fio condutor das entrevistas, utilizado informalmente de modo a convidar o entrevistado a falar de si e do seu jeito de atuar como médico.

. Formação e trajetória profissional;

. O que significa ser um "bom médico" no campo da Aids;

. Fontes de informação e atualização neste campo específico da Aids;

- Atendimento em equipe multidisciplinar;

- As facilidades e as dificuldades no atendimento às pessoas com HIV/Aids;

- As estratégias médicas utilizadas com os pacientes soropositivos;

. Particularidades no manejo de pacientes em relacionamentos sorodiscordantes;

- Comentários sobre as estratégias utilizadas pelos médicos em três vinhetas clínicas, a respeito de pacientes em relacionamentos sorodiscordantes.

\section{Resultados}

. Formação e trajetória profissional:

Foram seis os profissionais entrevistados, sendo duas mulheres e quatro homens, com idades entre trinta e três e cinquenta e nove anos. $\mathrm{O}$ tempo de graduação dos médicos, na época da realização das entrevistas, variou de sete a trinta e cinco anos, em instituições públicas de ensino como Universidade Federal do Rio de Janeiro (UFRJ), Universidade do Estado do Rio de Janeiro (UERJ) e Universidade Federal do Estado do Rio de Janeiro (UNIRIO), na cidade do Rio de Janeiro. Apenas um profissional escolheu cursar uma pós-graduação (Imunologia) em vez da residência. Dos cinco que fizeram residência, um escolheu fazê-la em gastrenterologia, dois deles a fizeram em DIP (Doenças infecto-parasitárias), e dois em clínica médica, sendo que um dos que escolheram a clínica médica optou por fazer em seguida outra residência, dessa vez em DIP.

Do total de entrevistados, quatro deles optaram por seguir também a carreira acadêmica, além do trabalho na assistência aos portadores de HIV/Aids, sendo que quatro cursaram mestrado e três, doutorado. Dois dos entrevistados 
trabalham também com pesquisa: um deles coordenando um projeto na DIP de um hospital universitário, e outro como bolsista de um núcleo ligado à pesquisa de vacinas para a Aids, na mesma universidade.

Apesar de todos os entrevistados possuírem - como característica comum - o atendimento aos pacientes com HIV/Aids, nem sempre isso foi uma escolha. Somente dois, os mais jovens, relataram interesse pela Aids como uma opção profissional. Os outros quatro médicos dizem que a Aids cruzou seus caminhos quando já estavam exercendo suas atividades profissionais.

Em relação ao tempo que estes profissionais atuam com pacientes com HIV/Aids, dois deles têm menos de dez anos (nove e sete anos), um tem dezesseis anos de experiência. Os outros três presenciaram o início da epidemia de Aids, com vinte e dois a vinte e quatro anos de trabalho neste campo.

. O que significa ser um "bom médico" no campo da Aids:

Dentre os requisitos para ser um "bom médico” na assistência aos pacientes com HIV/Aids, os entrevistados destacaram em primeiro lugar, a técnica, o conhecimento, a experiência e estar atualizado (aspectos objetivos). Além disso, deve desenvolver aspectos subjetivos na relação médico-paciente como sensibilidade, afetividade, criar vínculo, ser carinhoso, cuidadoso na abordagem, interessado pela vida do paciente, etc., matérias aprendidas na "vida" e não na faculdade de medicina.

- As facilidades e as dificuldades no atendimento às pessoas com HIV/Aids:

Quanto às dificuldades / facilidades no atendimento às pessoas vivendo com HIV/Aids, em geral, as falas sugerem:

(1) uma grande preocupação com a questão da "adesão", confundida com a adesão aos medicamentos;

(2) que a responsabilidade pela adesão é do paciente (o usuário de drogas, o adolescente, o desacompanhado, o morador de rua, com problemas sociais, o não-aderente);

(3) que a abordagem do tema sexualidade com o paciente ainda é assunto problemático, principalmente para os médicos recém-formados;

(4) que os efeitos adversos da medicação antirretroviral dificultam o tratamento (entendido como adesão aos medicamentos);

(5) que a não obediência às prescrições/orientações médicas interferem na condução do tratamento;
(6) que a revelação diagnóstica para o paciente e para outras pessoas é ainda um momento delicado;

(7) as dificuldades para convencer o paciente assintomático a tomar os remédios, pois ele nada sente;

(8) que há pouca disponibilidade dos médicos para cuidar desses pacientes e dos que possuem doenças crônicas, sem possibilidade de cura;

(9) que as questões institucionais, como carência de estrutura material e de recursos humanos, são obstáculos à melhoria da qualidade da atenção prestada, referentes aos serviços de saúde.

\section{Discussão}

Um dos primeiros pontos a ser destacado é que as estratégias médicas foram dirigidas às pessoas soropositivas de uma forma geral. A unidade casal, principalmente o arranjo sorodiscordante, não apareceu de forma significativa, a ponto de revelar estratégias específicas dedicadas a esse grupo. Diz um dos médicos entrevistados: "Não vejo nenhuma diferença no manejo destes pacientes (sorodiscordantes) comparados com os outros" (Médico 1, doravante chamado de M1). Consideramos, nesse estudo, que a estratégia médica dirigida aos casais sorodiscordantes, consciente ou não, é a produção de uma invisibilidade que se faz em função de um certo deslocamento do foco do olhar médico para a questão da adesão ao tratamento.

É notável a grande preocupação do grupo entrevistado com a adesão ao tratamento antirretroviral e, portanto, aos medicamentos. Vale esclarecer que a adesão aos medicamentos faz parte do tratamento das pessoas com HIV/Aids, mas, no cotidiano dos serviços, esses medicamentos são supervalorizados e confundidos como sinônimo de adesão ao tratamento.

Para que os médicos possam se concentrar "naquilo que realmente é considerado importante" ${ }^{\text {, }}$ devem adotar - como estratégia - a supressão de qualquer aspecto revelado durante o encontro com o paciente soropositivo, aspecto que não venha a contribuir com o diagnóstico objetivo da doença e com o tratamento a partir do instrumental disponível - os remédios - que, sem dúvida, têm melhorado a sobrevida dessas pessoas. Há pouco mais de dez anos, a maioria dos pacientes com HIV/Aids morria por falta de opções terapêuticas disponíveis, e, a partir da chegada do coquetel, essa realidade se transformou. 
Mudou a história da epidemia, que agora se assemelha às doenças crônicas, mas também reforçou a ideia daquilo "que é realmente importante" no tratamento do soropositivo, isto é, aderir ao medicamento disponível, pois esta foi a grande mudança no combate ao HIV/Aids ${ }^{1}$.

Para se chegar a entender o problema do paciente como sendo apenas a considerada adesão, necessariamente se está fazendo uma operação de subtração daquilo que não é importante, e esta operação já é, em si, uma estratégia (deliberada ou não) de não enxergar aquilo que, para este estilo de pensamento ${ }^{7}$, não resultará em nenhuma medida controlável. A estratégia do estilo de pensamento médico parece ser exatamente a de manter a subtração dos aspectos pouco controláveis ou subjetivos ${ }^{16}$, colocando-os de lado, valorizando (excessivamente, em muitos casos) a parte objetiva ou controlável do processo de tratamento. Quando falamos dos casais, estamos incluindo-os neste grupo de situações "não controláveis"; não existe uma estratégia positiva dirigida a eles. Eles não são considerados focos de intervenção médica para uma melhor adesão do(s) paciente(s) já infectado(s). A estratégia é, então, negativa no sentido de apagar essa condição de casal, como se apaga o contexto em que vivem os pacientes, suas relações familiares, seu modo de vida, suas expectativas, sua vida afetiva e seu jeito de amar. Essas considerações, contidas na palavra casal, não parecem pertencer à abordagem objetiva do médico - de acordo com este estilo de pensamento ${ }^{7}$.

A adesão ao tratamento envolve demandas ${ }^{17}$ pouco visíveis aos profissionais, elas ultrapassam a questão dos medicamentos. As estratégias médicas aqui relatadas traduzem as muitas formas de aproximação do médico com seu paciente, mas será a adesão sua única finalidade? Uma compreensão mais abrangente e realista deve conceber o sucesso do tratamento da Aids na dependência de múltiplos fatores, incluindo nestes, além de outros, os relacionados à pessoa portadora, seu parceiro (se houver), suporte social de amigos, familiares, profissionais e do público em geral, bem como apoio dos serviços públicos de saúde e da equipe multidisciplinar que trabalha nesses serviços.

Em virtude do alto valor atribuído à adesão podemos ser levados a compreender que a adesão é o principal fator e a causa determinante para o sucesso da terapia antirretroviral. $O$ fato é que muitas pesquisas ${ }^{18-24}$ destacam a fundamental importância da adesão para o tratamento, mas também expõem que a falta de aderência não é o único fator a contribuir para o fracasso da terapia antirretroviral e do tratamento da Aids. Portanto, não devemos considerar, como verdade absoluta, que a resistência viral aos medicamentos seja apenas resultado de falta de adesão. Segundo Rachid e Schechter ${ }^{25}$, a ocorrência de resistência viral é tida por especialistas como uma questão de tempo, mesmo tomando-se corretamente os medicamentos.

Quanto à dificuldade na abordagem do tema sexualidade com o paciente, é frequente a afirmação dos médicos de que não foram treinados para essa discussão na sua formação, de que não se sentem habilitados nem confortáveis ${ }^{2}$ a falar de temas 'tabu' e delicados como a sexualidade. O paciente percebe o desconforto do médico e, com isso, também se retrai, posto que este tema também pode ser desconfortável para si, levando de volta para casa prováveis dúvidas que poderiam ser esclarecidas na consulta pelo profissional de saúde. Como abordar o uso sistemático da camisinha, como forma de prevenção do parceiro negativo, com alguém numa relação sorodiscordante?

Essa coisa da abordagem com o paciente, a gente vai ganhando cancha com a prática e o tempo. $\mathrm{Na}$ época de residente era bem mais difícil e hoje a gente domina mais o assunto, [...] tem a experiência de vários pacientes anteriores, a gente já sabe como conduzir cada um. (M1)

Em relação à revelação diagnóstica, esse é, em geral, um momento tenso e delicado para todos os envolvidos com HIV/Aids - pacientes e médicos. Em especial para os casais, contar ao parceiro sobre o HIV pode implicar outras revelações (homo ou bissexualidade, uso de drogas, relação extraconjugal ou múltiplos parceiros). Nos sorodiscordantes, revelar para a família envolve a permissão do par positivo, há receio da coerção social e medo da discriminação. $\mathrm{O}$ assunto ora é tratado como individual ora como do casal, de acordo com Maksud 3 . Há o medo de ser rejeitado pelo parceiro devido ao HIV, o receio de infectar o parceiro negativo, e é comum a ocultação da condição de soropositivo para o parceiro. Se a relação de casamento é visível, o médico deve incentivar o paciente a revelar sua sorologia ao parceiro, recomendar o uso sistemático do preservativo, mesmo sabendo que culturalmente os casais, em relações estáveis, tendem a não fazem uso dele. Se o médico não percebe o arranjo do casamento, deixa de trabalhar temas extremamente relevantes para o tratamento de seu paciente. Se o paciente quiser, nós ajudamos a contar (sobre a soropositividade). (M3) [...] se o paciente está naquela fase 
que ele não tem condiçães de ouvir, não prescreva, porque não vai dar certo [...] Espera. (M4)

Quanto ao receio de não estar sempre disponível para seus pacientes, verifica-se que a relação médico-paciente, em geral, é permeada por fantasias a respeito da dependência do paciente em relação ao médico que o assiste. No processo de uma doença crônica, esse relacionamento tende a ser de longo prazo, e é natural que o médico sinta necessidade de se proteger (emocionalmente) do peso dessa dependência nele depositada. Quando nos referimos ao tratamento da Aids além de crônica, infecciosa - essa responsabilização parece ser vivenciada pelo médico de forma mais intensa e menos suportável, sendo necessária a presença de algo que faça uma mediação nessa tensão. Como nos aponta Sayd ${ }^{12}$, não é incomum que os remédios (os antirretrovirais, no caso da Aids) ocupem esse lugar de ponte entre doente e médico, fazendo parecer que o paciente deve depender mais dos medicamentos e menos da figura do médico. Acreditamos ser essa uma outra maneira de compreender o grande interesse dos médicos pela questão da adesão aos medicamentos.

[...] vai chegar um momento que não vou mais aguentar, não vou ter mais saco, não vou me dedicar a eles (pacientes) da mesma forma. Principalmente se eles não quiserem mais se dedicar a eles mesmos, quiserem se destruir..., e se eu os estou impedindo? o que é melhor para eles? e eu? estou me esgotando? Esse é o meu maior medo. (M6)

Este estudo permitiu ainda caracterizar um conjunto de regras direcionadas ao aspecto relacional na prática da clínica médica. São regras de conduta e atitudes, apreendidas normalmente como uma dimensão ética e como 'arte' na medicina. Arte essa referida pelos médicos, geralmente, como uma aptidão inata ('meu jeito'), que os habilitaria a lidar com as questões subjetivas, sociais e culturais presentes nessa prática. Analisando como a questão da arte é compreendida pela biomedicina, Schraiber ${ }^{26}$ afirma que, quando essa dimensão é incorporada pela prática clínica, é associada à esfera pessoal do médico como um dom natural, distante das interferências políticas, sociais e ideológicas. Essa também é uma estratégia, mas não é proposital, não faço isso para garantir a adesão, ajo naturalmente. Esse é o meu jeito, eu sou assim na minha vida. (M6) Eu não uso jaleco, [...] primeiro porque morro de calor, e segundo porque acho que não precisa criar essa distância. É meu jeito..., minha pedagogia, mas não foi pensado, foi espontâneo. (M2) Eu sou muito carinhoso com meus pacientes, mas isso é meu. (M6)
Ora, se os médicos consideram essas habilidades (jeitos) como pertencentes à esfera privada, é presumível pensarem que o que importa é intervir naquilo em que foram socializados coletivamente, deixando de fora os aspectos (subjetivos) do paciente, reconhecidos pelo médico como território privado, portanto, não merecedores de intervenção médica. A produção desta "invisibilidade" em relação aos casais torna-se necessária, para que outros temas, como a adesão aos medicamentos, ganhem espaço na consulta ambulatorial como questão passível de intervenção em nome do bom exercício da medicina, tal como lhes foi ensinado.

\section{Considerações finais}

Este estudo objetivou identificar as estratégias médicas dirigidas aos casais sorodiscordantes com HIV/Aids, e percebemos que, aparentemente, não havia nenhuma dirigida a esse grupo. Depois notamos, porém, que tornar invisível a condição de casal era uma estratégia, deliberada ou não, assim como colocar à parte outros aspectos subjetivos envolvidos no acompanhamento dessas pessoas. Chamou-nos a atenção um dado da pesquisa que não constava em nosso objetivo: a grande preocupação dos entrevistados com a "adesão ao tratamento", e a compreensão desta como sinônimo de "adesão aos medicamentos antirretrovirais". Na busca por uma estratégia em direção aos casais, percebemos que, para esses profissionais, qualquer estratégia é válida (até o afeto, carinho, etc.) para se atingir o objetivo maior: fazer com que os pacientes tomem sua medicação de forma correta.

A limitação de identificar e valorizar a medicina apenas como um saber científico, um conhecimento reducionista em sua dimensão biológica e que incorpora uma perspectiva de "verdade", tornou-se inquestionável na sociedade ocidental. Considerando-se esta noção de ciência, tornam-se ilegítimos outros saberes não biomédicos e o próprio saber dos sujeitos envolvidos na medicina ou na relação clínica. De acordo com Tesser ${ }^{27}$, as posturas biomédicas valorizam o saber esotérico e desqualificam o resto; recomenda a superação da tendência "controlista" da clínica biomédica e da saúde pública de pensar os sujeitos e grupos sociais apenas focando a submissão e a "aderência".

Em consequência desta leitura biológica, ficam de fora as possibilidades de entrar em contato com questões como a sorodiscordância e, 
portanto, de tratar e cuidar das pessoas nessa condição. Mais ainda, com a invisibilidade do casal, o parceiro negativo que era foco de prevenção fica excluído do processo de cuidado que o afeta diretamente, que é estar afetivamente ligado a uma pessoa soropositiva.

É na polaridade entre o tratar e o cuidar que caminham os modelos de atenção à saúde, geralmente com uma lógica curativa (voltada para o tratamento), e menos preventiva (orientada pelo cuidado). No plano da prática, é preciso criar espaços de intersubjetividade que nos ajudem a passar do tratamento ao cuidado, espaços esses que envolvem, necessariamente, uma dimensão dialógica. Deve-se considerar, além dos conhecimentos sobre as doenças, o conhecimento - que nem sempre temos - dos modos de viver (segundo Canguilhem $^{10}$ ) das pessoas com quem se interage nos serviços de saúde, a fim de construir projetos terapêuticos individualizados. Segundo Mattos ${ }^{28}$, na perspectiva da integralidade, os projetos tera- pêuticos emergem do diálogo/negociação, em que é possível compreender o contexto específico dos diferentes encontros entre profissionais de saúde e usuários de seus serviços. A escuta e o acolhimento, no plano do cuidado, somente poderão ser incorporados efetivamente à assistência, a partir de verdadeira comunicação entre usuários e profissionais. Nem os profissionais podem ser reduzidos às suas competências técnicas nem os usuários a passivos objetos de intervenção ${ }^{29}$.

Os profissionais de saúde interessados pelo paciente devem estar atentos às suas singularidades, para que, juntos, possam construir um projeto terapêutico viável. $\mathrm{O}$ casal que se apresenta junto nos atendimentos impõe outra dinâmica às abordagens das questões peculiares a esses serviços, exigindo melhor formação, mais desprendimento dos valores e crenças, e mais solidariedade e respeito dos profissionais em suas atribuições de promoverem saúde e esclarecimentos com qualidade e responsabilidade.

\section{Colaboradores}

AM Silva e KR Camargo Júnior participaram igualmente de todas as etapas de elaboração do artigo. 


\section{Referências}

1. Silva AM. Entre a cama e o ambulatório: a biomedicina e a vida sexual dos casais sorodiscordantes com HIV/Aids [dissertação]. Rio de Janeiro: Instituto de Medicina Social/Universidade do Estado do Rio de Janeiro; 2007.

2. Camargo Júnior KR. As ciências da AIDS \& A AIDS das ciências: o discurso médico e a construção da AIDS. Rio de Janeiro: Relume-Dumará, ABIA, Instituto de Medicina Social(IMS),Universidade Estadual do Estado do Rio de Janeiro(UERJ); 1994.

3. Maksud I. Casais com sorologias distintas para o HIV: questões iniciais para debate. In: Maksud I, Terto Júnior V, Pimenta MC, Parker R, organizadores. Conjugalidade e AIDS: A questão da sorodiscordância e os serviços de saúde. Rio de Janeiro: ABIA; 2002.

4. Brasil. Ministério da Saúde (MS). Secretaria de Vigilância em Saúde, PN de DST e Aids. Boletim Epidemiológico Aids e DST 2006; III(1).

5. Brasil. Ministério da Saúde (MS). Implicações Éticas do Diagnóstico e da Triagem Sorológica do HIV. Série Legislação no 2. Brasília: Ministério da Saúde (MS), Secretaria de Vigilância em Saúde, Programa Nacional de DST e AIDS; 2004.

6. Giacomozzi AI. Casamento e aids, uma questão de confiança [dissertação]. Florianópolis: Universidade Federal de Santa Catarina; 2005.

7. Fleck L. La génesis y el desarollo de un hecho científico - Introducción a la teoria del estilo de pensamiento y del colectivo de pensamiento. Madrid: Alianza Editorial; 1986.

8. Good BJ. Medicine, rationality, and experience - An anthropological perspective. Cambridge: Cambridge University Press; 1994.

9. Almeida E. As Razões da Terapêutica [tese]. Rio de Janeiro: Instituto de Medicina Social/Universidade do Estado do Rio de Janeiro; 1996.

10. Canguilhem GO. Normal e o Patológico. Rio de Janeiro: Forense Universitária; 1966.

11. Camargo Junior. KR. A Construção da AIDS [tese]. Rio de Janeiro: Instituto de Medicina Social/Universidade do Estado do Rio de Janeiro; 1993.

12. Sayd JD. Mediar, Medicar, Remediar: Aspectos da terapêutica na medicina ocidental. Rio de Janeiro: EdUERJ; 1998.

13. Camargo Junior KR. Medicina, Médicos, Doenças e Terapêutica. Rio de Janeiro: IMS/UERJ; 1998 (Série Estudos em Saúde Coletiva no 170/nov).

14. Becker HS. Métodos de Pesquisa em Ciências Sociais. São Paulo: Hucitec; 1999.

15. Minayo MCS. O Desafio do Conhecimento: pesquisa qualitativa em saúde. São Paulo, Rio de Janeiro: Hucitec, Abrasco; 1992.

16. Guedes C, Nogueira MI, Camargo Júnior KR. A subjetividade como anomalia: contribuições epistemológicas para a crítica do modelo biomédico. Cien Saude Colet 2006; 11(4):1093-1113.

17. Camargo Júnior KR. Das necessidades de saúde à demanda socialmente construída. In: Pinheiro R e Mattos RA, organizadores. Construção Social da Demanda: direito à saúde, trabalho em equipe, participação e espaços públicos. Rio de Janeiro: CEPESC/UERJ, Abrasco; 2005. p. 91-101.
18. Teixeira PR, Paiva V, Shimma E. Tá difícil de engolir? Experiências de adesão ao tratamento anti-retroviral em São Paulo. São Paulo: NEPAIDS; 2000.

19. Nemes MIB, Castanheira ERL, Santa Helena ET, Melchior R, Caraciolo JM, Basso CR, Alves MTSSB, Alencar TMDA, Ferraz DAS. Aderência ao tratamento por anti-retrovirais em serviços públicos de saúde no estado de São Paulo. Brasília: Ministério da Saúde; 2000.

20. Santos DF. Vivendo com HIV/AIDS: Cuidado, tratamento e adesão na experiência do Grupo Com Vida. [dissertação]. Rio de Janeiro: Instituto de Medicina Social/Universidade do Estado do Rio de Janeiro; 2001.

21. Guimarães M da S, Raxach JC. A Questão da Adesão: os desafios impostos pela aids no Brasil e as respostas do governo, de pessoas e da sociedade. Impulso 2002; 13(32):69-90.

22. Bastos FI, Hacker M, Terto Júnior V, Raxach JC, Bessa M, Parker R, Berkman A, Remien R. Aderência à Terapia Anti-retroviral de Alta Potência no Rio de Janeiro, Brasil: Revisão de Alguns Aspectos Conceituais e Principais Achados Empíricos do Projeto ABIA,Columbia University. In: Parker R, Galvão J, Pimenta MC, Terto Júnior V, organizadores. Aprimorando o debate: anais do seminário Conquistas e desafios na assistência ao HIV/AIDS. Rio de Janeiro: ABIA; 2002. p. 33-45.

23. Cardoso GP, Arruda A. As representações sociais da soropositividade e sua relação com a observância terapêutica. Cien Saude Colet 2005; 10(1):151-162.

24. Malta M, Petersen ML, Clair S, Freitas F, Bastos FI. Adherence to antiretroviral therapy: a qualitative study with physicians from Rio de Janeiro, Brasil. Cad Saude Publica 2005; 21(5):1424-1432.

25. Rachid M, Schechter M. Manual de HIV/AIDS. $5^{\mathrm{a}}$ ed. Rio de Janeiro: Revinter; 2000.

26. Schraiber LB. O Médico e seu Trabalho, Limites da Liberdade. São Paulo: Hucitec; 1993.

27. Tesser CD. Medicalização social (I): o excessivo sucesso do epistemicídio moderno na saúde. Interface Comun Saude Educ 2006; 9(18):61-76.

28. Mattos RA. A integralidade na prática (ou sobre a prática da integralidade). Cad Saude Publica 2004; 20(5):1411-1416.

29. Silva NEK, Oliveira LA, Figueiredo WS, Landroni MAS, Waldman CCS, Ayres JRCM. Limites do trabalho multiprofissional: estudo de caso dos centros de referência para DST/Aids. Rev Saude Publica 2002; 36(Supl. 4):108-116.

Artigo apresentado em 08/03/2009

Aprovado em 24/07/2009

Versão final apresentada em 15/05/2009 